\title{
A integração da Realidade aumentada em sala de aula: a pesquisa aplicada em colégios públicos do litoral Paranaense
}

Alex de Cássio Macedo, UFPR, proflecao@gmail.com

Anderson Roges Teixeira Góes, UFPR, artgoes@ufpr.br

RESUMO: O presente trabalho tem o objetivo de discutir a integração da tecnologia digital Realidade aumentada como recurso em sala. Participaram da pesquisa 123 estudantes do ensino médio de cinco turmas de colégios de um município do litoral paranaense. Fez parte da metodologia a criação do material didático impresso e interativo a um aplicativo PolyedRA especialmente desenvolvido para ser aplicado nesta pesquisa. Verificou-se que o ambiente de sala de aula mediada pela Realidade aumentada foi capaz de proporcionar aprendizagem, cooperação, confiança, autonomia e interações entre os estudantes e com o professor. Assim, esta pesquisa traz contribuições para novas investigações sobre a integração de tecnologias digitais em sala de aula.

Palavras-chave: Realidade aumentada, Ensino e aprendizado de matemática, Tecnologia educacional.

ABSTRACT: The present work aims to discuss the integration of digital technology Augmented Reality as a room resource. A total of 123 high school students participated in the study of five groups of schools in a municipality on the coast of Paraná. It was part of the methodology the creation of printed and interactive didactic material to a PolyedRA application specially developed for this research. It was found that the classroom environment mediated by augmented reality was able to provide learning, cooperation, trust, autonomy and interactions between the students and the teacher. Thus, this research brings contributions to new research on the integration of digital technologies in the classroom..

Keywords: Augmented Reality, Mathematics Teaching and Learning, Educational Technology.

\section{Introdução}

A sociedade atual é dinâmica exigindo versatilidade, flexibilidade e disposição para enfrentarmos o dia a dia que está repleto de informação. A escola, como parte integrante da sociedade, não pode ser diferente, precisa que seja dinâmica e igualmente versátil para conseguir cumprir com a missão de preparar cidadãos capazes de viver na sociedade com tais requisitos.

Faz-se necessário que os recursos atuais presentes na sociedade também estejam no ambiente escolar, não somente como forma de acessibilidade, mas também como forma de proporcionar a construção de conhecimento por meio de diversas informações. Em 2005, Almeida já abordava tal assunto ao afirmar que,

Inserir-se na sociedade da informação não quer dizer apenas ter acesso à tecnologia de informação e comunicação (TIC), mas principalmente saber utilizar essa tecnologia para a busca e a seleção de informações que permitam a cada pessoa resolver os problemas do cotidiano, compreender o mundo e atuar na transformação de seu contexto. Assim, o uso da TIC com vistas à 
criação de uma rede de conhecimentos favorece a democratização do acesso à informação, a troca de informações e experiências, a compreensão crítica da realidade e o desenvolvimento humano, social, cultural e educacional. Tudo isso poderá levar à criação de uma sociedade mais justa e igualitária (ALMEIDA, 2005, p. 110).

Passado mais de uma década, ainda a escola necessita desmistificar as diversas tecnologias e empregá-las em prol de uma Educação mais eficiente. Para isso, são necessárias metodologias que favoreçam a formação do estudante, futuro cidadão e trabalhador, tornando-o agente principal na construção de seu conhecimento. Esse desafio vem sendo discutido por diversos autores há muito tempo (ALMEIDA, 2005; MORAN, 2003; KENSKI, 2012), no entanto parece que, apesar dos avanços, muitas vezes pontuais, estamos em um movimento circular, voltando sempre ao ponto de partida. Há esforços grandiosos para mostrar a necessidade de integrar as tecnologias atuais (sobretudo as tecnologias digitais - TD), mas as escolas continuam em metodologias ultrapassadas e não utilizam recursos que visam tornar o ambiente mais dinâmico que possibilite a transformação de informações em conhecimento.

Para tanto, este texto busca contribuir na discussão sobre o uso de dispositivos móveis em sala de aula, uma vez que, apresenta o uso de uma tecnologia considerada emergente - a Realidade aumentada (RA) - no processo de ensino e aprendizagem. A pesquisa apresenta uma sequência de atividades, envolvendo um aplicativo e um material impresso interativo, utilizadas em uma série de aulas previamente planejadas. Com isso, procuramos investigar a integração da RA em dispositivos móveis no processo de ensino e aprendizagem de Geometria Espacial no Ensino Médio.

Os resultados dessa pesquisa apontam articulações teóricas e práticas, demonstrando ser possível a integração dessa tecnologia no ambiente escolar e como pode contribuir com processo de ensino e aprendizagem.

\section{Integração das diferentes tecnologias no ambiente escolar}

$\mathrm{Na}$ ecologia da sala de aula é o professor e estudantes que dão vida aos processos de ensino e aprendizagem, por meio da comunicação e das relações que são estabelecidas entre si, as quais podem ser permeadas por atitudes de autoridade, alteridade, cooperação, cumplicidade e parceria (COSTA; PRADO, 2015).

Com isso, o ambiente de sala de aula deve ser analisado como um dos recursos essenciais para que a aprendizagem ocorra de maneira plena. Esse ambiente será, cada vez mais, um ponto de partida e de chegada, um espaço importante, mas que deve ser combinado com outros espaços e outros recursos para ampliar as possibilidades de atividades de aprendizagem (MORAN, 2003).

A concepção de aprendizagem exaustivamente disseminada nos dias de hoje destaca a importância das interações entre sujeitos e objetos para a aprendizagem (SERAFIM; SOUZA, 2011). Assim, investigar e vivenciar a sala de aula é, sobretudo, interrogar as atitudes dos atores envolvidos, alunos e professores, suas interações e relações com saberes e objetos de aprendizagem (GÓES; GÓES, 2015).

Levar o aprendiz ao centro do processo é o desafio das novas metodologias e ações que buscam inovar no processo ensino e aprendizagem. Pretende-se com isso propor que o estudante seja ativo, participante e consciente de seus avanços e limitações, que construa o conhecimento e não simplesmente o receba como uma caixa de correio repleta de correspondências, com vários conhecimentos envelopados, que não se relacionam e chegam aos montes sem que haja uma organização. (ALMEIDA, 2005; MORAN, 2003; KENSKI, 2012; GÓES; GÓES, 2015). 
Dar sentido e organizar os conceitos a serem aprendidos é função do professor que deve facilitar e acompanhar a construção dos conhecimentos do aprendiz. O professor deve propor maneiras e caminhos para que o estudante chegue a seus objetivos, discutindo, revendo e criando novas situações de aprendizagem (GÓES; GÓES, 2015). Nesse contexto, conforme Kenski (2012) e Moran (2003), os recursos tecnológicos devem mediar estas relações, fornecendo novas maneiras e abordagens aos problemas e situações de aprendizagem, facilitando a comunicação e ampliando as possibilidades de interação entre estudante - professor - conhecimento (e agora) o mundo.

Para Macedo (2018), muitos professores consideram o uso de telefones celulares, tablets e smatphones em sala como negativo e proíbem seu uso por parte dos estudantes. No estado do Paraná, local onde essa pesquisa se situa, há uma lei estadual ${ }^{i}$ vigente que proíbe o uso desses equipamentos em sala de aula, a não ser para fins pedagógicos. No entanto, a exclusão desses equipamentos como tecnologias educacionais por muitos profissionais da educação acarreta a desconsideração de três fatores: (1) é inevitável que as tecnologias atuais estejam presentes no ambiente escolar e na vida das pessoas; (2) muitos desses aparelhos, hoje disponíveis no mercado, possuem um poder de processamento superior a muitos computadores que anos atrás eram o sonho de consumo de qualquer professor em suas aulas e (3) a referida lei permite o uso pedagógico, que atualmente tem sido pelas diversas áreas de desenvolvimento educacional, massivamente incentivada e investigada.

Faz-se necessário, portanto, discutir o uso de dispositivos móveis em sala de aula, sobretudo munidos de tecnologias emergentes, tais como, a RA, com vistas a consolidálas como recursos importantes no processo de ensino e aprendizagem.

\section{Metodologia}

Esta pesquisa trata de um estudo de caso qualitativo em Educação em que se busca, por meio do acompanhamento de uma sequência de atividades, investigar a integração da RA em dispositivos móveis no processo de ensino e aprendizagem de Geometria espacial no Ensino médio. Foram analisadas cinco turmas, envolvendo três turmas do ensino regular e duas do curso de formação de docentes, sendo duas delas matutinas, uma vespertina e duas noturnas.

A pesquisa ocorreu em encontros semanais de 100 minutos durante seis semanas em cada uma das turmas, sendo aplicado pelo professor-pesquisador, ou seja, o professor regente da turma sendo parte de sua metodologia em sala de aula.

A sequência de atividades fez uso de um material didático impresso, considerado interativo por estar associado a um aplicativo de dispositivo móvel desenvolvido para a pesquisa. A necessidade da criação de um aplicativo próprio para a pesquisa surge da dificuldade de encontrar um aplicativo existente gratuito em língua portuguesa que atendesse aos interesses da investigação que propomos. O nome dado ao aplicativo, PolyedRA, é composto de elementos que integram justamente sua concepção: "Polyed" fazendo referência, respectivamente, a palavra poliedro em grego, a sigla correspondente à tecnologia utilizada (Realidade Aumenta) e comumente utilizado para aplicações para dispositivos móveis.

O material didático impresso desenvolvido para a pesquisa foi elaborado com base nas diretrizes e nos livros didáticos fornecidos pelo Programa Nacional do Livro Didático (PNLD), nos quais os conteúdos e atividades contêm os marcadores (exemplo na Figura 1) ao serem focalizados pela câmera do dispositivo, disparam a interação do aplicativo com o material impresso e, assim, pode-se visualizar os objetos virtuais correspondentes. 


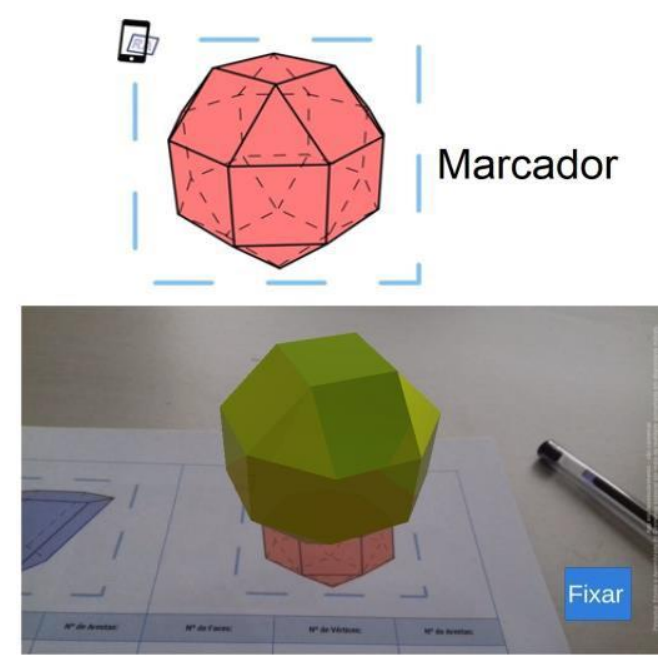

Tela do Aplicativo

FIGURA 1 - Imagem do marcador e da tela do aplicativo com inserção do objeto virtual à cena.

Cabe ressaltar que os dispositivos móveis necessários para gerar as imagens por meio dos marcados pertenciam aos estudantes e não foi necessário um laboratório de informática equipado nem tampouco outro espaço físico. Para tanto, foi realizado um levantamento inicial que apontou a viabilidade de aplicação da pesquisa nas turmas envolvidas, já que nelas a maioria dos estudantes possuíam dispositivos móveis, o que permitiu a realização das atividades em duplas ou trios, portanto houve em alguns casos compartilhamento de aparelhos.

$\mathrm{Na}$ análise da pesquisa procuramos levantar aspectos observáveis quanto à integração deste recurso em um ambiente "natural" de sala de aula, uma vez que o professor regente das turmas é o próprio pesquisador. Foram realizados registros em áudio, vídeo e a aplicação de questionários para obtenção dos dados. Por se tratar de uma pesquisa que envolve adolescente, submetemos a pesquisa à análise e aprovação do Comitê de Ética em pesquisa da Universidade Federal do Paraná e da superintendência da Secretaria de Estado da Educação do Paraná, recebendo autorização para implementar a pesquisa em sala de aula.

O levantamento de dados foi realizado por meio de observações e análises do material produzido durante as aulas, bem como a aplicação de questionários, sendo um inicial e outro ao final dos encontros.

O que se buscou ao analisar os dados coletados foi verificar as contribuições da RA na obtenção de um ambiente que promova as interações, o interesse e a motivação necessária à troca de saberes e construção de reflexões (SERAFIM; SOUZA, 2011), destacando os trabalhos individuais em sala e o trabalho coletivo (MACEDO; SILVA; BURIOL, 2016; OLIVEIRA, 2016), bem como, a motivação e a curiosidade ajudam na busca desses saberes (NOVAL, 2013).

Não foi encontrado, na literatura pesquisada, trabalho em que se realiza uma avaliação da manutenção do interesse e da motivação em utilizações prolongadas da RA em sala de aula, constituindo-se esse um ponto de contribuição desta pesquisa a este campo de investigação. Fez parte dessa investigação, portanto, a observação do efeito motivacional e do interesse ao longo dos encontros. 


\title{
4. Análise dos trabalhos selecionados
}

Com essas concepções são relacionadas às observações e dados que evidenciem (ou não) as contribuições da RA na obtenção de um ambiente que promova as interações, o interesse e a motivação necessária à troca de saberes e construção de reflexões. (SERAFIN; SOUZA, 2011).

Ao traçar o perfil dos participantes, logo no questionário inicial foi possível perceber que apenas 36\% dos participantes preferem trabalhos individuais em sala, o que favoreceu o trabalho em grupo. Embora houvesse certa liberdade neste ponto,pois se percebeu ao longo dos encontros é que participantes foram naturalmente se unindo em grupos sendo raros os casos de alunos que iniciaram e concluíram os roteiros de aprendizagem trabalhando exclusivamente de maneira individual. Concluiu-se, então, que o trabalho coletivo, além de favorecer a aprendizagem, deve promover um ambiente de socialização e reflexão.

Dentre os diversos momentos o trecho que segue evidencia um momento de motivação e interação promovido pela mediação da RA, no qual, em uma das turmas, uma participante questionou o tamanho do quadro da Monalisa e isso provocou uma discussão e uma pesquisa. No diálogo a seguir é apresentada a discussão entre os estudantes participantes (PA12 e PA07) e o professor-pesquisador (PP).

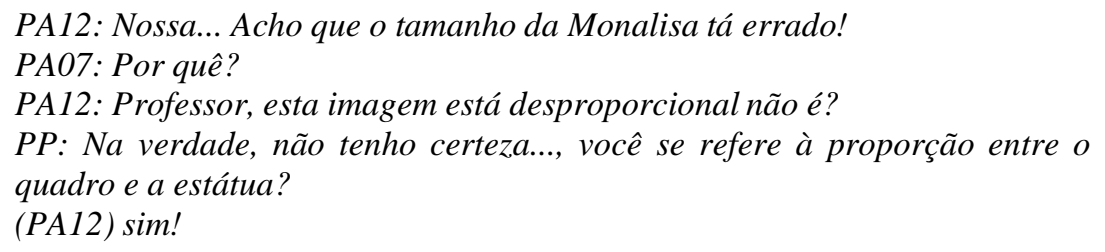

Enquanto isso, o participante PA07 começou a realizar uma pesquisa na internet para saber as dimensões reais do quadro e da estátua (a internet utilizada foi do próprio aluno) e o diálogo prosseguiu:

\author{
PA07: Aqui ó.. A Monalisa tem 77 por 53! \\ PA12: E a estátua? \\ PA07: Como é o nome da estátua \\ PA12: Davi!... Michelangelo! \\ PA07: Tem $517 \mathrm{~cm}$ de altura e uma base de $199 \mathrm{~cm}$ de diâmetro \\ PA12: Falei!... Ela parece maior do que é... Né, professor! \\ PA07: Será? \\ PP: Só verificando quantas vezes a estátua é mais alta que o quadro... $\mathrm{Na}$ \\ realidade e na imagem $3 D$ !
}

Esses participantes realizaram uma breve discussão, analisando as dimensões e ainda, outros alunos ficaram atentos e se interessaram pela discussão. Uma solução foi apresentada: para que pudessem medir a imagem em RA, focaram o celular e com uma régua mediram as imagens, anotando as dimensões encontradas. Depois disso, os participantes solicitaram novamente a presença o professor pesquisador, e ocorreu um novo diálogo:

PA07: Professor... A (fulana) me ajudou a segurar o celular e então medi com a régua a altura da Monalisa e da estátua!

PA12: Deu 1,5 cm ela e quase $10 \mathrm{~cm}$ o Davi

PP: E aí, qual foi a conclusão?

PA12: Agora tem que dividir? Pra saber o quanto um é maior que outro? 


\begin{abstract}
$P P:$ Sim!
(Então o PA07 acionou a calculadora do celular e inseriu as medidas)

PA07: Nas medidas aqui da internet ficou.... 517 dividido por 77... deu 6,714.. eee.. Um monte de número... [...] ... E 10 dividido por 1,5... Deu ...6,6666...(como é?)...dízima...

PA12: Então ficou 6,7 na real e 6,6 na imagem! O que significa?

PP: Que a estátua é aproximadamente 6,7 vezes maior que o quadro,... e... na imagem da cena é 6,6 vezes maior

PA07: Dá pra dizer que é quase a mesma proporção.. Né?

PA12: Mas eu não estava toda errada... Na imagem o quadro é um pouquinho maior que na verdade....
\end{abstract}

Casos similares ocorreram durante o segundo encontro nas diferentes turmas. Essa recorrência permitiu identificar que os alunos mudaram sua maneira de produzir, buscando em diferentes recursos subsídios para a construção de seu aprendizado e reflexões.

O diálogo ilustrado mostra a mobilização gerada por uma experiência de vida e um questionamento inesperado. Ao desenvolver a cena em RA, não se pensou na possibilidade de discutir as dimensões reais do quadro, porém os questionamentos da participante PA12 produziu pesquisa instantânea, contribuindo com toda a turma, enriquecendo a atividade.

Embora não intencional, a integração da RA se deu pelo fato de que a simples presença virtual do quadro na discussão provocou uma dinâmica diferente, que talvez não houvesse em outras situações.

São essas formas de questionamentos e busca de saberes pelos participantes que reafirma o aspecto motivacional gerado pela RA (NOVAL, 2013; MACEDO; SILVA; BURIOL, 2016; COLPANI, 2015), o aumento do interesse dos participantes pelo conteúdo mediado (DUNCAN, 2014; MACEDO; SILVA; BURIOL, 2016) e a possibilidade de interações entre os membros da equipe enriquecendo um ambiente de trabalho colaborativo de reflexões e conjecturas (MACEDO; SILVA; BURIOL, 2016; OLIVEIRA, 2016).

Ainda, tais observações são reafirmadas pelos participantes no questionário final. Os dados obtidos endossam essa impressão, pois quando perguntados sobre o trabalho em grupo, $80 \%$ dos participantes concordaram, mesmo que parcialmente, que realizar as atividades em grupo aumentou a confiança (GRÁFICO 1).

GRÁFICO 1: RESPOSTAS DOS PARTICIPANTES QUANDO A CONFIANÇA E TRABALHO EM GRUPO

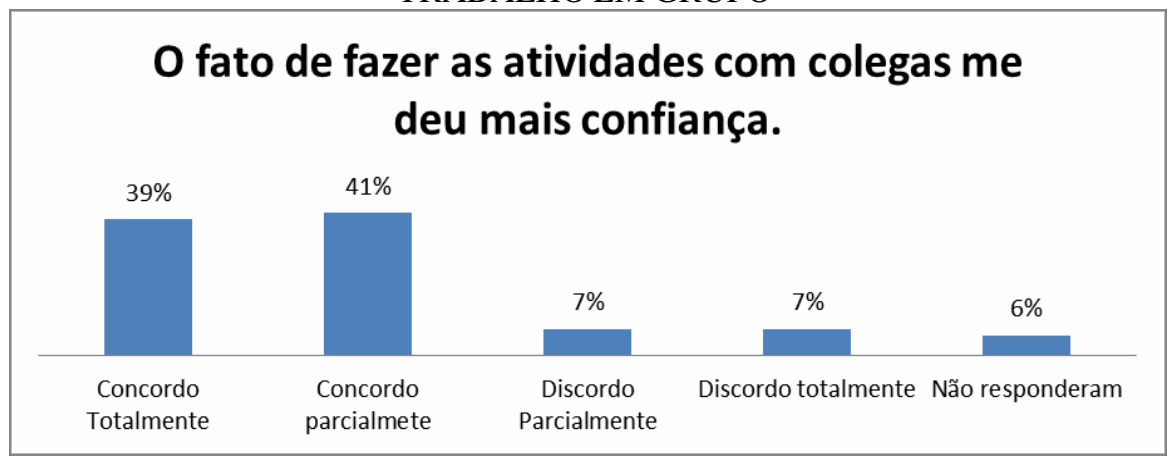

Fonte: os autores, 2019. 
A motivação também foi avaliada pelos participantes no questionário final, pode-se perceber (GRÁFICO 2) que a maioria das avaliações (63\%) concordaram com a afirmação de que a RA motivou o estudo de alguma maneira.

GRÁFICO 2: RESPOSTAS DOS PARTICIPANTES RELACIONADAS À MOTIVAÇÃO.

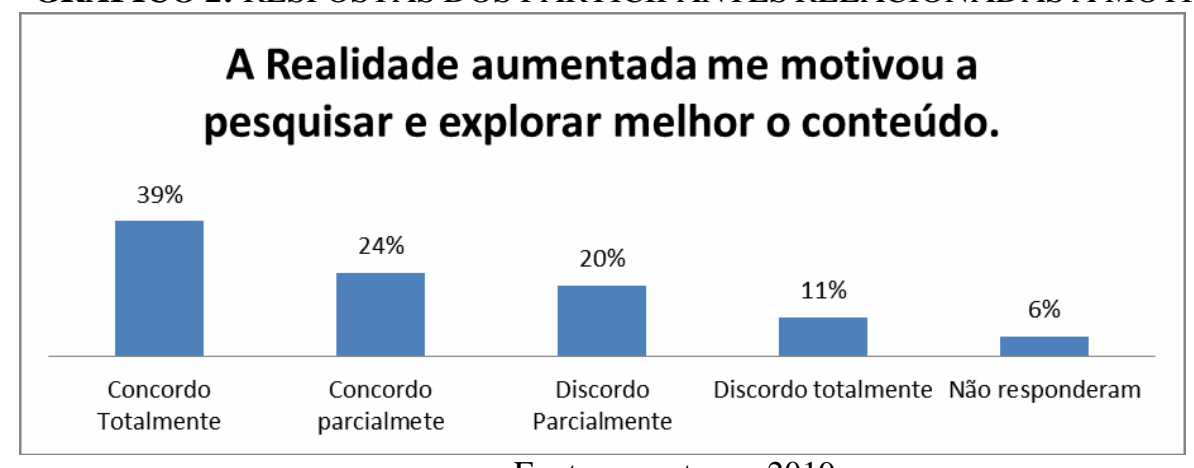

Fonte: os autores, 2019.

No perfil tecnológico dos participantes, $66 \%$ dos participantes afirmaram nunca ter utilizado um aplicativo de RA. Esse fato denota a novidade desse recurso para os participantes, durante os primeiros encontros foi muito perceptível a curiosidade e a ansiedade em saber como funcionava e o que tinha "escondido" em cada marcador do roteiro de aprendizagem.

Já com a aplicação da sequência de atividades finalizada, o questionário final mostrou que a impressão dos participantes, quanto ao aspecto inovador da metodologia e do apoio tecnológico utilizado, provocou a curiosidade e, consequentemente, a mobilização em relação ao conteúdo; pois $74 \%$ dos participantes concordaram mesmo que parcialmente, com a afirmação de que a curiosidade os aproximou do conteúdo da aula (GRÁFICO 3).

GRÁFICO 3: QUESTIONÁRIO FINAL: AFIRMAÇÃO RELATIVA À CURIOSIDADE.

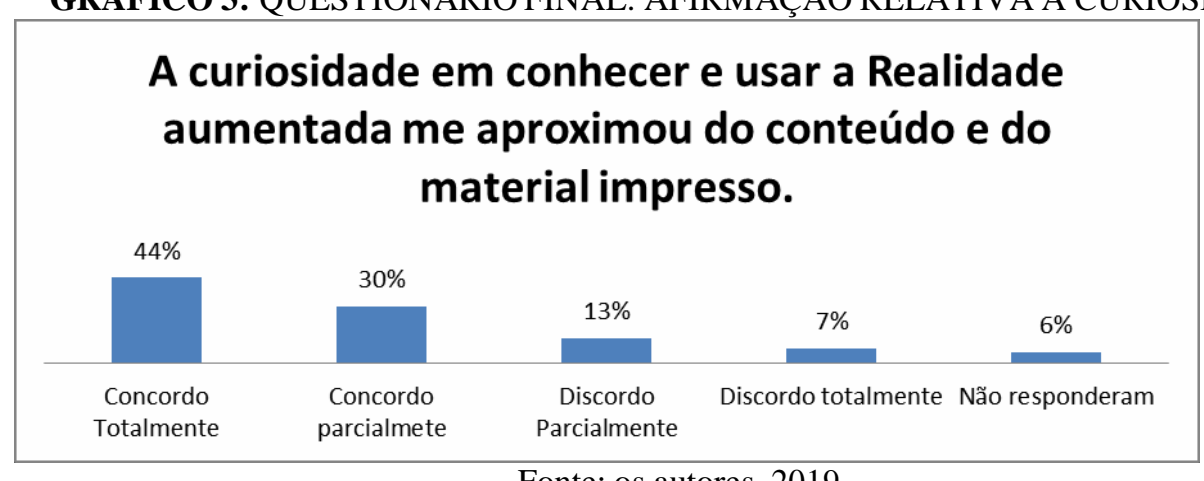

Fonte: os autores, 2019.

Fez parte dessa investigação a verificação do efeito motivacional e do interesse ao longo dos encontros, que na maioria dos registros destaca a predominância de participantes focados nas discussões e na realização das atividades.

Em consonância com estas observações, a avaliação dos participantes quanto a esse aspecto também validou esta interpretação, uma vez que $70 \%$ dos participantes discordaram com a redução da motivação ao longo dos encontros, conforme Gráfico 4. 
GRÁFICO 4: RESPOSTAS RELACIONADAS AO EFEITO MOTIVACIONAL AO LONGO DOS ENCONTROS.

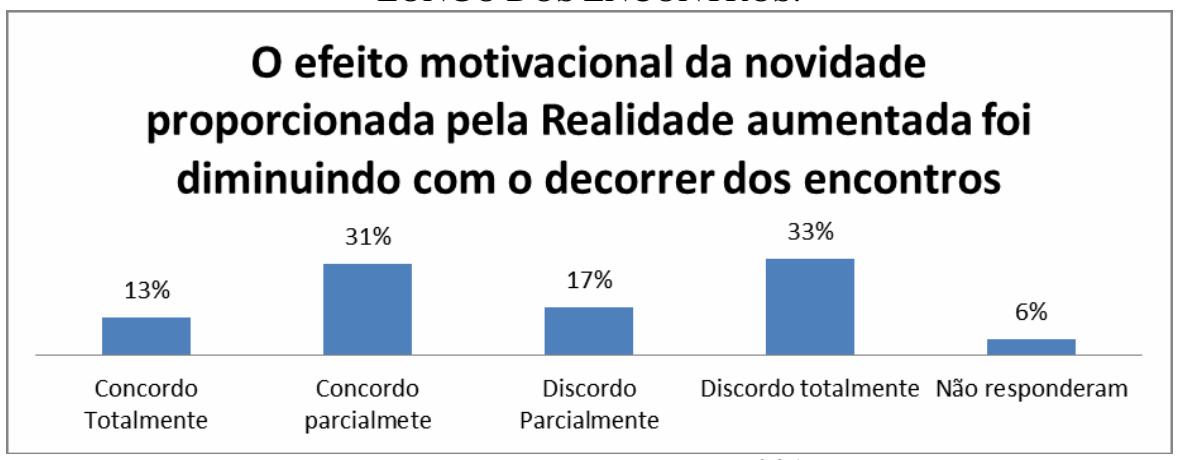

Fonte: os autores, 2019.

Quanto às interações entre os participantes mediadas pela RA percebidas durante os encontros pelas observações realizadas, além da intensificação dessas discussões durante os encontros, os participantes expressaram essa mesma opinião quando perguntado sobre o potencial das simulações nas interações ocorridas (GRÁFICO 5), com $74 \%$ de concordância.

GRÁFICO 5:RESPOSTAS RELACIONADAS À INTERAÇÃO ENTRE OS PARTICIPANTES.

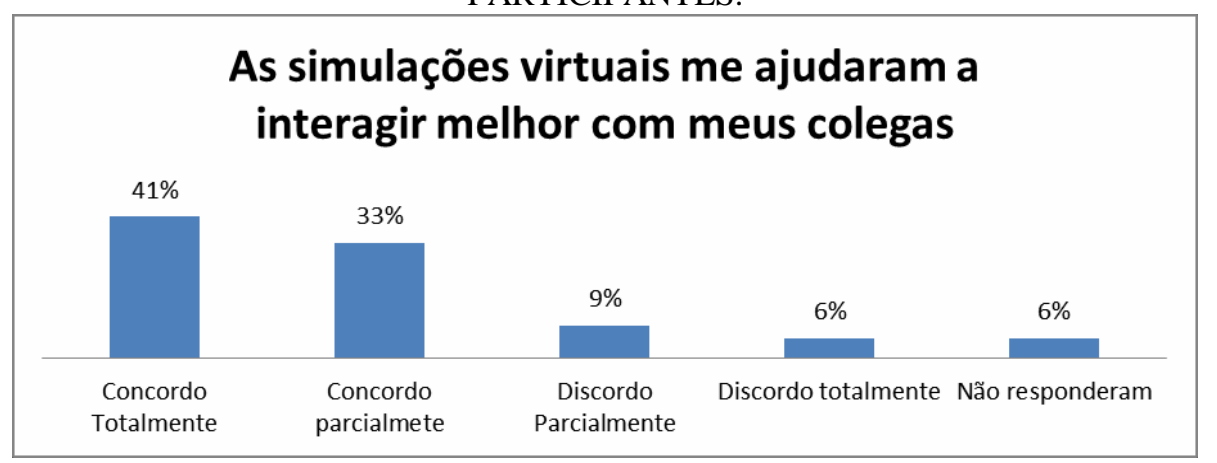

Fonte: os autores, 2019.

Do ponto de vista do ambiente em sala de aula, pode-se perceber que a RA favoreceu aspectos importantes na manutenção de um clima de aprendizagem, potencializando o trabalho colaborativo, as reflexões, o interesse, as interações entre professor - aluno - conteúdo, manteve o efeito motivacional ao longo dos encontros. Foi possível, também constatar durante as atividades que a RA é de grande ajuda na sala de aula, não deixando de lado a importância de outros recursos pedagógicos, como o quadro e giz, assim como o diálogo e a interatividade entre docentes e discentes para a evolução da aprendizagem (GOMES, 2015). Sendo importante ressaltar que o recurso em estudo deve ser integrado a fim de potencializar o ambiente de aprendizagem e não simplesmente substituir qualquer que seja de seus elementos.

\section{Considerações finais}

A pesquisa discutiu a integração da tecnologia digital RA como recurso em sala. Apresentou ainda a análise das contribuições dessa tecnologia um ambiente em sala de aula, promovendo as interações, o interesse e a motivação necessária à troca de saberes e construção de reflexões.

Por meio do levantamento de dados descritivos e audiovisuais foi possível analisar o caso educacional em um ambiente natural de realidade escolar, uma vez que o estudo 
de caso foi vivenciado por meio da integração da RA em cinco turmas de dois colégios do litoral paranaense ao longo de seis encontros.

Os objetivos traçados pela pesquisa foram estabelecer diversas correlações entre os fatos ocorridos, as impressões dos participantes e os parâmetros teóricos obtidos ao longo da investigação, no que diz respeito à realização dos trabalhos individuais e coletivos em sala, bem como a potencialidade da motivação e da curiosidade na busca de saberes e nas interações. Assim, ao responder o questionamento de nossa pesquisa, pode-se perceber que no caso educacional investigado, a RA foi um recurso de apoio ao ensino que possibilitou, dentre outros aspectos, criar um ambiente de aprendizagem, cooperação, confiança e autonomia, enriquecendo o material didático e as interações entre os estudantes e entre esses e o professor. Ainda, favoreceu a integração de mídias, a visualização de objetos geométricos e as reflexões sobre eles, com destaque para o aspecto lúdico envolvido.

Quanto ao ambiente sala de aula, a integração da RA, como recurso pedagógico de mediação mostrou a capacidade de potencializar o trabalho colaborativo, as reflexões, o interesse e as interações entre professor-estudante-conteúdo, além de manutenção do clima de aprendizagem ao longo dos encontros.

Finalmente é importante destacar dois pontos: a RA não é um recurso substitutivo de qualquer um dos elementos existentes e que compõe a sala de aula atualmente, sua integração deve contribuir no processo, sendo mais um apoio e uma possibilidade ao professor; há uma necessidade urgente de novas metodologias e recursos na preparação de uma educação do futuro, para isso, professores, estudantes e todos envolvidos na educação necessitam assumir uma mudança de postura, sem a qual qualquer inovação é infrutífera. (MORAN, 2003; KENSKI, 2012; GÓES; GÓES, 2015).

Dessa forma, este trabalho contribui com duas questões: (1) apresentar uma vivência de integração da tecnologia digital em sala de aula, em especial na escola pública e (2) fornecer como um produto desta vivência o material didático e o aplicativo desenvolvido, disponibilizado ${ }^{\text {ii }}$ a quem desejar utilizar, no intuito de contribuir com a sociedade, em especial as comunidades educacionais; uma vez que a RA ainda é pouco explorada no ambiente educacional, fato observado em nossa revisão de literatura.

\footnotetext{
${ }^{i}$ Lei estadual $n^{\circ} 18118$ de junho de 2014 , que dispõe sobre a proibição do uso de aparelhos/equipamentos eletrônicos em salas de aula para fins não pedagógicos no Estado do Paraná.

${ }^{\text {ii }}$ Site para download do material e do aplicativo utilizado na pesquisa. $<$ http://twixar.me/JlF1 $>$
}

\section{Referências}

ALMEIDA, M. E. B. Tecnologia na escola: criação de redes de conhecimentos. In: ALMEIDA, M. E. B. MORAN.J. M. (Orgs). Integração das tecnologias na educação. Secretaria de Educação a Distância. Brasília. Ministério da Educação: SEED, 2005. Disponível em: < http://www.dominiopublico.gov.br/download/texto/me000701.pdf >. Acesso em 26/01/2017.

COSTA, N. M. L. D.; PRADO, M. E. B. B. A Integração das Tecnologias Digitais ao Ensino de Matemática: desafio constante no cotidiano escolar do professor. Perspectivas da Educação Matemática: Revista do programa de pós-graduação em educação matemática da universidade federal de mato grosso do sul (UFMS), Campo Grande, v. 8 n.16, p. 99-120, 2015.

COLPANI, R. AR+G ATIVIDADES EDUCACIONAIS: Um aplicativo de RA com Gamification para auxiliar no processo de ensino-aprendizagem de alunos com 
deficiência intelectual. Dissertação (Mestrado) - Programa de Pós-graduação em Ciência a Computação, Universidade Federal de São Paulo. Sorocaba, 2015.

DUNCAN, S. D. A. M. Uso de Técnicas de RA no Ensino de Pirâmide. Dissertação (Mestrado) - Programa de Pós-Graduação em Matemática (ProfMat), Universidade Estadual do Norte Fluminense. Campos dos Goytacazes, 2014.

GÓES, A. R. T.; GÓES, H. C. Ensino da Matemática: concepções, metodologias, tendências e organização do trabalho pedagógico. Curitiba: Editora InterSaberes, 2015.

GOMES, N. A. Possibilidades do uso da RA na visualização de elementos matemáticos. Dissertação (Mestrado) - Programa de Pós-Graduação em Matemática (ProfMat), Universidade Federal de Goiás. Jataí, 2015.

KENSKI, V. Educação e tecnologias: O novo ritmo da informação. Campinas, SP: Papirus, 2012.

MACEDO, A. D. C. Ensino e aprendizado de geometria por meio da Realidade aumentada em dispositivos móveis: um estudo de caso em colégios públicos do litoral paranaense. Dissertação (Mestrado) - Programa de Pós-graduação em Educação: Teoria e Prática de Ensino, Universidade Federal do Paraná. Curitiba, 2018.

MACEDO, A. D. C.; SILVA, J. A. D.; BURIOL, T. M. Usando Smartphone e RA para estudar Geometria espacial. RENOTE- Novas tecnologias na Educação, Porto Alegre - RS, v. 14, n. 2, dezembro 2016.

MORAN, J. Gestão inovadora da escola com tecnologias. In: VIEIRA, A. Gestão educacional e tecnologia. São Paulo: Avercamp, 2003. p. 151-164.

NOVAL, M. D. M. RA no ensino da Matemática: um caso de estudo. Dissertação (Mestrado) - Mestrado em Tecnologias da Informação e Comunicação - Universidade de Trás-os-Montes e Alto Douro. Vila Real - Portugal. 2013.

OLIVEIRA, P. S. D. Procedimentos Pedagógicos para o processo ensino aprendizagem de matemática no Ensino Médio: Intervenção pela realidade aumentada. Dissertação (Mestrado) - Programa de Pós-graduação em Ensino de Ciências, Universidade Federal de Itajubá. Itajubá, 2016.

SERAFIM, M. L.; SOUSA, R. P. Multimídia na educação: o vídeo digital integrado ao contexto escolar. Campina Grande: EDUEPB, 2011. 